\title{
Brincadeiras Infantis e Natureza: Investigação da Interação Criança-Natureza em Parques Verdes Urbanos
}

\author{
Yasmin Sauer Machado \\ Universidade Federal de Santa Catarina, Florianópolis, SC, Brasil \\ Patrícia Maria Schubert Peres \\ Dayse da Silva Albuquerque \\ Programa de Pós-Graduação em Psicologia da Universidade Federal de Santa Catarina, \\ Florianópolis, SC, Brasil \\ Ariane Kuhnen ${ }^{1}$ \\ Departamento de Psicologia e Programa de Pós-Graduação em Psicologia da Universidade \\ Federal de Santa Catarina, Florianópolis, SC, Brasil
}

\section{Resumo}

Estudos vêm mostrando que o contato com a natureza traz benefícios cognitivos, sociais, físicos e psicológicos para as crianças, influenciando seu desenvolvimento. Nos ambientes naturais, as crianças realizam diversos tipos de brincadeiras e desenvolvem a capacidade de imaginação. No presente estudo, com o objetivo de conhecer a interação criança-natureza nas brincadeiras, foram observadas 30 crianças de dois a dez anos em dois parques verdes urbanos de Florianópolis (SC). Para isso, foi elaborado um protocolo de observação e utilizada a técnica de mapeamento comportamental centrado-na-pessoa. Nos dois contextos, a areia foi o elemento natural mais utilizado nas brincadeiras construtivas. Nessas brincadeiras, as crianças juntavam a areia com potes plásticos, pás ou com as próprias mãos a fim de construir algo. Outros elementos da natureza como a vegetação, a água e a pedra foram observados com menor frequência nas brincadeiras. A vegetação foi utilizada em um dos parques em brincadeira turbulenta de subir em árvore. A água apareceu em brincadeiras turbulentas de esparramar água e jogála em outras crianças, e a pedra apareceu em brincadeiras construtivas. Preservar a presença desses elementos em áreas naturais ou incluí-los em áreas planejadas implica na ampliação de oportunidades de recreação para as crianças.

Palavras-chave: Psicologia ambiental, desenvolvimento infantil, brincadeiras, natureza.

\section{Nature and Children's Play: Investigation of Children - Nature Interaction in Urban Greens Parks}

\begin{abstract}
Studies have shown that contact with nature brings cognitive, social, physical and psychological benefits to children, influencing their development. In natural environments, children play jumping, running, digging, building, hiding, climbing trees, and develop the capacity of imagination in make-believe play.

Endereço para correspondência: Universidade Federal de Santa Catarina, Centro de Filosofia e Ciências Humanas, Departamento de Psicologia, Laboratório de Psicologia Ambiental, sala 11B, Campus Universitário, Trindade, Florianópolis, SC, Brasil 88040-970. Fone: (48) 3721-8574. E-mail: lapamcfh@gmail.com, yasminsm@gmail.com,pmschu@hotmail.com, albuquerquepsi@hotmail.com e ariane@cfh.ufsc.br
\end{abstract}


In the present study, which aimed to understand the child-nature interaction in play, 30 children aged 2 to 10 years were observed in two urban green parks of Florianópolis, southern Brazil (SC). Thus, one observation protocol was developed using the technique of person-centered behavioral mapping. In both contexts, sand was the natural element most used in constructive play. Children were observed gathering sand with plastic shovels or pots to build something. Other elements such as vegetation, water and stone were observed less frequently in play behaviors. In one of the parks, vegetation was used in a turbulent play with a child climbing a tree. Water was used in turbulent play of spreading water and throwing it at one another, and stones were used in constructive play. The preservation of these elements in natural areas or their inclusion in planned areas implies in the expansion of recreational opportunities for children.

Keywords: Environmental psychology, child development, play, nature.

\section{Los Juegos de Niños y la Naturaleza: La Investigación de la Interacción Niño-Naturaleza en los Parques Verdes Urbanos}

\section{Resumen}

Los estudios han demostrado que el contacto con la naturaleza trae beneficios cognitivos, sociales, físicos y psicológicos para los niños, que influyen en su desarrollo. En ambientes naturales los niños realizan trucos como saltar, correr, construir, esconderse. Con el objetivo de conocer la interacción niño-naturaleza en los juegos, 30 niños de dos a diez años se observaron en dos parques verdes de la ciudad de Florianópolis (SC). Así que un protocolo de observación se desarrolló y utilizó la cartografía técnica conductual centrada en persona. En ambos contextos, la arena era el elemento natural más usado en el juego constructivo. En estos juegos, los niños reunieron la arena con palas de plástico o con sus propias manos, para construir algo. Se observaron otros elementos de la naturaleza como la vegetación, el agua y la piedra con menor frecuencia en los juegos. La vegetación se utilizó en juegos con los árboles, el agua apareció en el juego donde los niños lanzaban el agua en otros niños, y la piedra apareció en el juego constructivo. Preservar la presencia de estos elementos en los espacios naturales o incluirlos en áreas planificadas implica la expansión de las oportunidades de recreación para los niños.

Palabras clave: Psicología ambiental, desarrollo infantil, juego, naturaleza.

A brincadeira é um fenômeno considerado universal, presente no cotidiano de crianças de diversas culturas, que tem servido como característica definidora da infância (Fiaes \& Bichara, 2009). O brincar é um comportamento complexo e multifacetado e a maioria de suas definições constituem-se insuficientes (Hansen, Macarini, Martins, Wanderlind, \& Vieira, 2007). Muitas vezes, não há diferença entre sua forma e a de outros comportamentos solitários, como a exploração do ambiente, por exemplo (Pinho, 2004). A identificação deste comportamento é facilitada pela sua visibilidade e por altos níveis de atividade, assim como por algumas características comuns à sua ocorrência como o riso e a descontração (Yamamoto \& Carvalho, 2002).
A função do brincar no desenvolvimento infantil ainda não é clara, sendo que a concepção que mais predomina e influencia atualmente é de que a brincadeira auxilia no treinamento de habilidades que serão úteis no futuro. Pode-se afirmar que, na brincadeira, os meios justificam os fins, ou seja, esta parece não servir para nenhum propósito imediato, e esse talvez seja o critério de maior concordância para definir o conceito (Santos \& Dias, 2010).

Em função do que se sabe sobre a importância das brincadeiras, espaços de lazer são planejados de modo a atender as necessidades de desenvolvimento das crianças e garantir sua segurança, sendo que os parques infantis são um exemplo da intenção de promover desafios mo- 
tores (Fjørtoft, Kristorffersen, \& Sageie, 2009). No entanto, nem sempre as atividades e espaços planejados às crianças correspondem às preferências delas próprias no uso de um lugar (Rasmussen, 2004). Estudos sobre preferência mostram que os espaços com natureza são aqueles que as crianças mais gostam e utilizam, quando estão disponíveis (Korpela, Kÿtta, \& Hartig 2002; Samborski, 2010; Sargisson \& McLean, 2012; Wells, 2000). Isso se explica pelas emoções vivenciadas nas atividades que as crianças realizam na natureza (Jansson, 2008) ou por serem espaços onde elas estão fora da supervisão dos pais (Valentine \& McKendrick, 1997).

A presença da natureza em espaços abertos de lazer proporciona maior diversidade de brincadeiras às crianças. Em pesquisa realizada por Sargisson e McLean (2012), foram comparadas preferências de 4597 crianças entre zero e doze anos no uso de elementos naturais e elementos construídos em 56 parques infantis na Nova Zelândia. Resultados indicaram que 14\% do tempo gasto pelas crianças nesses locais envolveram brincadeiras com elementos naturais, sendo que os meninos utilizaram mais esses elementos que as meninas. As crianças apresentaram maior tendência de utilização de elementos da natureza quando havia uma maior diversidade deles disponíveis, sendo que estes proporcionam um maior repertório de brincadeiras que elementos construídos.

Ao analisar entrevistas realizadas com 105 pais, professores e administradores de 59 escolas, Dyment e Bell (2008) constataram que a variedade de vegetação e topografia presente nas escolas diversifica o repertório de brincadeiras das crianças, proporcionando brincadeiras para meninos e meninas de todas as idades, assim como exercício físico. Esses ambientes convidam as crianças a realizarem várias atividades físicas como pular, correr, cavar, construir, esconder-se, subir em árvores. Corroborando com essa pesquisa, Azlina e Zulkiflee (2012) afirmam que os recursos encontrados no ambiente escolar influenciam na atividade física da criança e que ambientes naturais são fonte de diversificação de brincadeiras e de aprendizado.
O uso que crianças fazem dos espaços abertos e a presença de certos elementos da natureza também está relacionado aos tipos de brincadeiras que elas desenvolvem. A presença de vegetação tem sido relacionada a brincadeiras do tipo construtiva, turbulenta e simbólica (Fjørtoft, 2004; Jansson, 2008; Samborski, 2010). A areia é um elemento muito presente em áreas de parques infantis e brincadeiras construtivas estão relacionadas à presença desse elemento (Czalczynska-Podolska, 2014). Elementos da topografia como declives e rochas, por exemplo, proporcionam brincadeiras que envolvem maior vigor físico, como subir e escorregar (Fjørtoft, 2004). Elementos soltos como pequenas pedras, gravetos, folhas e frutos também são utilizados pelas crianças em brincadeiras de construção e faz de conta (Kernan, 2010; Kuh, Ponte, \& Chau, 2013; Malone \& Tranter, 2003; Refshauge, Stigsdotter, \& Petersen, 2013; Schäffer \& Kistemann, 2012). A relação da criança com a água foi investigada por Said (2008), que identificou 83 tipos de atividades de natureza física, cognitiva e social em crianças que utilizavam rios e riachos de uma região tropical.

As oportunidades de interação com natureza que a criança estabelece através das brincadeiras trazem importantes benefícios para o seu desenvolvimento. As brincadeiras turbulentas que envolvem subir em árvores, rochas e declives apresentam às crianças desafios motores e as estimulam sensorialmente (Fjørtoft, 2004). Brincadeiras construtivas e de faz de conta em caixas de areia, em meio à vegetação e com elementos soltos da natureza oportunizam tanto a socialização (Czalczynska-Podolska, 2014) quanto a busca da privacidade (Samborski, 2010). Além disso, a exposição às áreas verdes tem um efeito restaurador da atividade cognitiva (Wells, 2000; Wells \& Evans, 2003). Outros estudos exploram ainda benefícios de longo prazo do contato com a natureza. Experiências permanentes na natureza, através de programas de educação ambiental ou atividades recreativas favorecem o aumento tanto do conhecimento sobre a ecologia dos lugares como da afetividade em relação a natureza, contribuindo para o desenvolvimento de atitu- 
des e comportamentos pró-ambientais (Chawla, 1998, 2007; Collado, Staats, \& Corraliza 2013; Kahn, 2002) e valorização da presença de natureza nos espaços urbanos (Wang, Liu, Pan, Zhao, \& Zhang, 2012).

Nos espaços urbanos onde a natureza torna-se escassa e onde, mundialmente, se concentram mais de $50 \%$ das crianças (Fundo das $\mathrm{Na}$ ções Unidas para a Infância [UNICEF], 2012), os parques ganham importância ao proporcionar a interação da criança com a natureza. Com o crescimento desorganizado das cidades e os problemas de mobilidade e segurança nas ruas, os pais não permitem que seus filhos caminhem ou brinquem fora de casa em espaços abertos devido à percepção de insegurança em relação a esses espaços (Romero et al., 2001; Timperio, Salmon, Telford, \& Crawford, 2005). Os parques urbanos, como os parques infantis e o pátio da escola, são lugares que os pais escolhem levar os seus filhos para realizar atividade física e brincar de forma segura e onde o contato com a natureza torna-se mais acessível.

Tendo em vista os benefícios que o contato com a natureza pode proporcionar às crianças, compreender o uso dos parques urbanos e as interações com a natureza nesses espaços torna-se necessário. No presente estudo, essa interação é entendida como uma ação intencional da criança de interagir com as propriedades de um elemento da natureza nas brincadeiras. Sendo assim, dada a importância da natureza como uma condição promotora do brincar, o presente trabalho teve como objetivo a caracterização da relação criança-natureza nas brincadeiras em dois parques verdes urbanos de Florianópolis - SC, com o intuito de ajudar a compreender a relação entre a configuração dos espaços e as atividades que as crianças realizam.

\section{Método}

A pesquisa teve caráter descritivo e exploratório e pretendeu caracterizar o uso que crianças realizam de recursos naturais de espaços verdes urbanos nas brincadeiras. Para isso, utilizou-se o método de observação e a técnica do mapeamento comportamental centrado-na-pessoa. A técnica permite acesso do pesquisador a comportamentos da criança em seu ambiente cotidiano, sendo, portanto, amplamente utilizada em estudos que visam caracterizar a relação da criança com os espaços abertos (Luz \& Kuhnen, 2013; Raymundo, Kuhnen, \& Soares, 2011; Refshauge et al., 2013; Sargisson \& Mclean, 2012).

\section{Participantes}

Participaram desse estudo 30 crianças (16 meninas e 14 meninos) com idades entre dois e dez anos. Foram observadas 15 crianças em cada parque, selecionadas de acordo com a idade aparente e recrutadas em um ponto do parque demarcado pela pesquisadora.

\section{Locais de Observação}

A coleta de dados ocorreu em dois parques urbanos de Florianópolis (SC), identificados como Parque 1 e Parque 2. Os parques foram selecionados por conveniência com base em dois critérios: ter natureza preservada acessível ao visitante e ser visitado frequentemente por famílias.

O Parque 1 está localizado na região central de Florianópolis e possui 22 hectares de área, que conjuga o resguardo de Mata Atlântica, com estruturas como trilhas, parquinho, viveiro, quiosques, quadras e área cercada para animais, como coelhos, jacarés-de-papo-amarelo, cágados e jabutis. O Parque 2 está situado ao sul da ilha, distando $24 \mathrm{~km}$ do centro de Florianópolis. Possui uma área de $20 \mathrm{~km}^{2}$ que abriga uma lagoa de água doce de aproximadamente $5 \mathrm{~km}^{2}$ e resguarda remanescentes de restinga da Mata Atlântica. A área destinada ao lazer é estruturada com um parque infantil, corredores de acesso à lagoa, trilhas e áreas para piquenique.

\section{Procedimentos de Coleta de Dados}

Após aprovação do projeto pelo Comitê de Ética em Pesquisa com Seres Humanos da Universidade Federal de Santa Catarina, sob protocolo $\mathrm{n}^{\circ}$ 17068013.2.0000.0121, foram realizadas observações naturalísticas com o uso da técnica de mapeamento comportamental centrado-na-pessoa, que corresponde ao acompanhamento 
dos movimentos e atividades de um sujeito durante um intervalo pré-determinado de tempo no contexto de estudo. A cada sessão de observação, o pesquisador define o indivíduo, registra seus comportamentos e o local onde ocorreram as atividades (Fernandes \& Elali, 2008). É importante definir um período de adaptação por se tratar de uma técnica intrusiva (Pinheiro, Elali, \& Fernandes, 2008). Nessa pesquisa, foi definido o período de cinco minutos para habituação tanto do pesquisador quanto do sujeito observado.

Trabalhou-se a partir da noção de instante congelado de tempo, ou seja, os registros representavam "fotografias mentais" de momentos específicos das atividades das crianças (Pinheiro et al., 2008). As observações foram periódicas, com amostragem de tempo. Foram observados e registrados os comportamentos do mesmo indivíduo em intervalos de três minutos ao longo do período de trinta minutos totais de observação, ou seja, cada criança foi observada em dez momentos alternados, totalizando dez comportamentos registrados por criança.

Para identificar o local em que a criança se encontrava, dividiu-se a planta baixa dos parques em setores, de acordo com características físicas que diferenciavam cada área. O Parque 1 foi fragmentado em sete setores: (a) setor 1 (S1) - constitui-se em uma área com equipamentos de parque infantil e árvores; (b) setor 2 (S2) é uma área de piquenique com mesas, bancos e gramado; (c) setor 3 (S3) - caracteriza-se por uma pista de chão batido para caminhada com vegetação ao redor; (d) setor 4 (S4) - é formado por um lago com a presença de animais como cágados e jacarés e um recinto com coelhos e jabutis, além de uma área com aparelhos de ginástica para adultos e mesas de piquenique; (e) setor 5 (S5) - refere-se à área da entrada do parque que inclui portaria, sede, lago, trilhas e uma porção da vegetação do parque; (f) setor 6 (S6) engloba o horto do parque e (g) setor 7 (S7) - é a área central do parque onde se encontra o prédio administrativo, bebedouros e banheiros. Foi estabelecido um ponto inicial em S7 para abordar os participantes e iniciar a observação.

O Parque 2 foi dividido em quatro setores: (a) setor 1 (S1) - formado por uma área que in- clui a entrada do parque com estacionamento, sede administrativa, banheiros, área de piquenique com mesas e bancos e equipamentos de parque infantil; (b) setor 2 (S2) - composto pelos corredores de acesso à lagoa com vegetação em seu entorno; (c) setor 3 (S3) - caracterizado por uma faixa de areia e gramado, cercada por um lado pela lagoa e por outro pela vegetação e (d) setor 4 (S4) - abrange toda a extensão da lagoa. No S1 foi estabelecido um ponto para abordar os participantes e iniciar a observação.

O recrutamento dos participantes ocorreu no ponto delimitado pela pesquisadora em cada um dos parques - no setor 7 no Parque 1 e setor 1 no Parque 2. Primeiramente, obtinha-se a autorização dos responsáveis pela criança e apresentava-se o Termo de Consentimento Livre e Esclarecido (TCLE), a fim de que o responsável pudesse assiná-lo e fosse iniciada a observação a partir daquele mesmo ponto.

Ressalta-se que antes de iniciarem as observações efetivas deste estudo, foi realizado um teste de concordância entre observadores, necessário para garantir a precisão e fidedignidade das categorias comportamentais observadas e registradas. No mínimo, $70 \%$ de acordo entre os observadores é exigido ao se usar um conjunto de categorias pré-definidas (Fagundes, 1999). Para isso, a mesma criança foi observada em uma sessão de trinta minutos, na mesma hora, mas de forma independente por dois observadores. Posteriormente, os registros foram comparados, a fim de se verificar em que medida havia concordância entre eles. Foram realizadas algumas sessões de observações que exigiram modificações no protocolo até que se atingisse o formato que forneceu o índice de concordância de $80 \%$.

\section{Instrumento}

O instrumento utilizado para registrar os comportamentos foi um protocolo de observação adaptado de Cordazzo, Westphal, Tagliari, Vieira e Oliveira (2008). Neste protocolo encontravam-se as categorias que deveriam ser consideradas: (a) o local (setor) do parque que a criança se encontrava no momento; (b) o tipo de brincadeira realizada pela criança e (c) o elemento da natureza que estava sendo utilizado na 
brincadeira. Ao lado das categorias havia um espaço para registro de detalhes extras, considerados relevantes para a pesquisa, mas que não eram contemplados pelas categorias previamente definidas.

\section{Análise dos Dados}

O tratamento dos dados coletados contou com o auxílio do programa estatístico Microsoft Office Excel, onde foram digitados em planilhas dados relativos a: setor que a criança se encontrava, brincadeira que estava realizando e, se fosse o caso, o elemento da natureza utilizado. Esses dados foram quantificados obtendo-se a frequência de cada categoria de análise (tipos de brincadeiras, setores do parque e elementos da natureza) e tabelas e gráficos foram gerados para uma melhor visualização dos resultados. Os dados obtidos nos parques foram analisados separadamente, tendo em vista suas características distintas.

As brincadeiras realizadas pelas crianças podiam ser de três tipos: construtiva, faz de conta ou turbulenta. A brincadeira construtiva refere-se à manipulação de objetos com o objetivo de criar algo. O faz de conta envolve o imaginário da criança, implica a representação de um objeto por outro e pode apresentar a reprodução de papéis (mamãe, papai, professora, super-herói, etc.) e a brincadeira turbulenta é o tipo de atividade que abrange comportamentos como pular, correr, saltar, empurrar, puxar, perseguir, mergulhar, nadar e/ou lutar. Dessa forma, a brincadeira turbulenta ocorre quando a criança exibe movimentos bruscos e vigorosos, manifestando expressão facial hilariante. Essas categorias não são excludentes tendo em vista que a criança pode, por exemplo, estar construindo um castelo (brincadeira do tipo construtiva) fingindo ser uma princesa (brincadeira de faz de conta). Nesses casos, foram marcadas no protocolo simultaneamente duas categorias (Cordazzo et al., 2008).

Os elementos da natureza poderiam ser: pedra, areia, animal, vegetação e água. A categoria vegetação englobava os componentes naturais: árvore, galho, folha, flor e semente. É importante ressaltar que a interação com esses elementos só era anotada no protocolo de observação quando a criança incorporava os componentes na brincadeira e esta se encontrava tocando ou os segurando nas mãos.

\section{Resultados}

A seção de Resultados está organizada da seguinte forma: primeiramente, são apresentados os resultados alcançados no Parque 1 e posteriormente no Parque 2. Para cada um desses parques está descrito como se deu a ocupação dos setores, o tipo de brincadeira realizada pelas crianças e as brincadeiras que envolveram interação com os elementos da natureza.

\section{Parque 1}

No total, foram registrados 147 comportamentos nos sete setores do parque. Das 15 crianças observadas no Parque 1, nove delas, ao entrarem no local, dirigiram-se para o $\mathrm{S} 4$, que possui o lago e o recinto com animais. Além de ser o setor para o qual as crianças encaminhavam-se primeiramente, ele se caracterizou como o mais ocupado por elas, com 64 ocorrências. O S1 foi o segundo mais ocupado, com 47 ocorrências, seguido do S3, com 28. Com sete ocorrências, o setor central do parque (S7) foi o quarto mais utilizado pelas crianças e o menos utilizado foi o setor da área de piquenique (S2), com apenas uma ocorrência. O S5, que é o da entrada do parque, e o S6, delimitado pelo horto, não foram utilizados pelas crianças. A ausência de utilização desses setores pode ser explicada pelo fato do S5 estar localizado na entrada do parque e as observadoras ficarem dentro do parque, na área central. Isso implica que, se as crianças utilizavam esse setor ao entrarem no parque, o comportamento não era observado. Além disso, também não era observado se os participantes o utilizavam na saída, pois os trinta minutos de observação acabavam antes dos participantes irem embora. O S6 não foi utilizado porque era delimitado por cercas e fechado aos finais de semana - período em que ocorreram as observações.

No que diz respeito às brincadeiras realizadas pelas crianças, três tipos foram observados, 
conforme a Figura 1. A brincadeira que predominou foi a turbulenta, com 39 ocorrências, representando $80 \%$ do total de observações. As atividades realizadas pelas crianças, as quais foram caracterizadas como pertencentes a esse tipo, deram-se principalmente no S1 - ocorrência de 23 brincadeiras - com a utilização dos elementos construídos do parquinho como: gangorra, balanço e escorregador, e no S4, com 11 ocorrências desse tipo de brincadeira, que se constituíram em jogar bola e no uso dos equipamentos da área de ginástica para adultos. Além desses dois setores, três brincadeiras turbulentas foram observadas no S7 que envolveram brincadeiras de pular obstáculo, correr e balançar, e duas no S3, caracterizadas por brincadeiras de correr e descer desníveis.

A segunda brincadeira mais frequente foi a construtiva, com oito ocorrências. Neste tipo de brincadeira, as crianças exerceram atividades que envolveram pintar um livro de colorir, construir um copo com papelão, fazer montes de areia e brincar de bola de sabão. Três ocorrências da brincadeira construtiva foram observadas no S1, área do parque infantil, e cinco ocorrências no S4, área do lago. A brincadeira do tipo faz de conta obteve duas ocorrências, as quais foram realizadas com brinquedos trazidos de casa (boneco, helicóptero e disco), em que se fantasiava que estes voavam. Uma ocorrência da brincadeira de faz de conta foi observada no S1 e outra no S4.

Do total de 49 brincadeiras observadas, apenas em quatro ocorreu interação com a natureza. As quatro brincadeiras ocorreram no $\mathrm{S} 1$, sendo duas delas turbulentas e as outras duas construtivas. O elemento natural "vegetação" foi utilizado em uma das brincadeiras turbulentas e se caracterizou por uma criança subindo na árvore. O elemento natural "areia" foi usado em outra forma de brincadeira turbulenta, em que o participante se arrastava na areia. Ela também foi utilizada em duas brincadeiras construtivas observadas com uma criança fazendo um monte de areia.

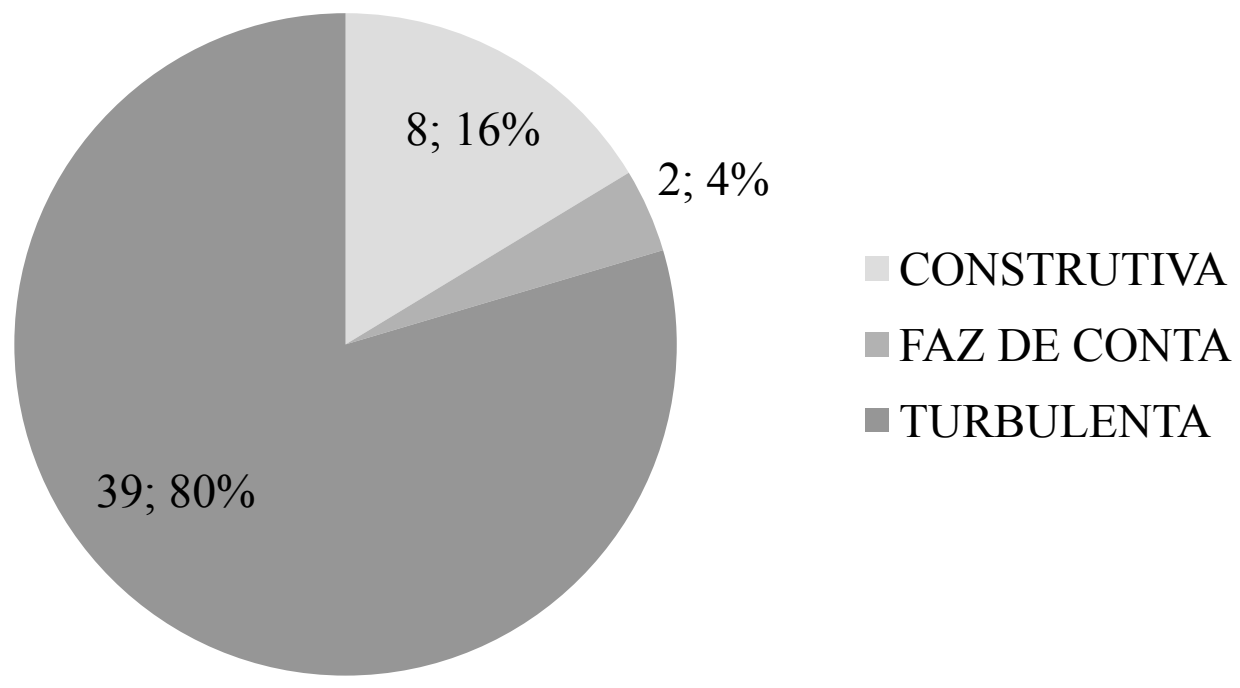

Figura 1. Tipos de brincadeiras realizadas pelas crianças/Parque 1.

\section{Parque 2}

No Parque 2, foram observados 150 comportamentos nos quatro setores do local. O setor mais ocupado foi o $\mathrm{S} 4$, representado pela lagoa, com 99 ocorrências. O S3 foi o segundo mais ocupado, com 46 ocorrências, seguido do S1, a área de piquenique, que obteve cinco ocorrências. O S2, caracterizado pelos corredores de acesso a lagoa, não obteve nenhuma ocorrência. Dado que os participantes foram recrutados na entrada do parque e os cinco minutos iniciais foram utilizados para adaptação pesquisador/ sujeito observado, a ocupação do S2 não foi registrada.

A brincadeira que mais ocorreu foi do tipo turbulenta com 47 ocorrências, como mostra a 
Figura 2. Destas, 44 foram no $\mathrm{S} 4$ e eram atividades que envolviam nadar, correr, pular e mergulhar. As três brincadeiras turbulentas restantes ocorreram nos setores S1 e S3. No S1, ocorreram duas brincadeiras turbulentas nas quais foram utilizados os equipamentos do parque infantil, e no S3 foi observada uma criança agitando um remo de caiaque no ar.

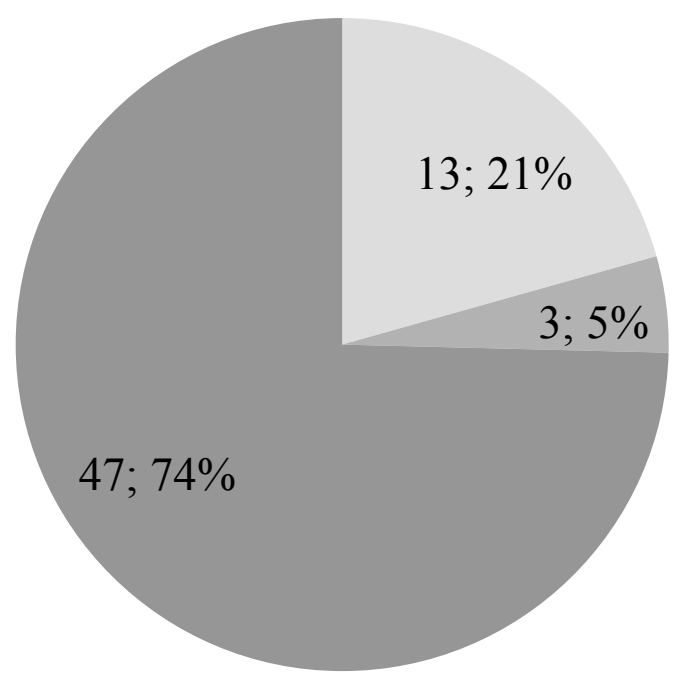

Com 13 ocorrências, a brincadeira construtiva foi a segunda mais realizada pelas crianças. Dentre elas, oito foram observadas no $\mathrm{S} 4$ e cinco brincadeiras no S3. Representando 5\% das brincadeiras observadas, a do tipo faz de conta foi a menos realizada pelas crianças, sendo que uma ocorrência foi observada no S3 e duas ocorrências no S4.

Figura 2. Tipos de brincadeiras realizadas pelas crianças/Parque 2.

Do total de 63 ocorrências de brincadeiras, 25 envolveram elementos da natureza. Em todas as brincadeiras construtivas e do tipo faz de conta observadas, foram utilizados elementos da natureza. A brincadeira que mais ocorreu com elementos da natureza foi a construtiva com 13 ocorrências, seguida da brincadeira do tipo turbulenta com cinco ocorrências e, por fim, a do tipo faz de conta com três ocorrências.

Como mostra a Figura 3, o elemento da natureza mais utilizado nas brincadeiras foi a areia. Esse elemento foi usado em dez ocorrências de brincadeiras do tipo construtiva, uma ocorrência do tipo turbulenta e duas ocorrências do tipo faz de conta. As brincadeiras construtivas foram observadas nos setores S3 e S4 e consistiram em atividades de juntar a areia com potes plásticos, pás ou com as próprias mãos a fim de construir algo. A brincadeira turbulenta observada foi uma "guerra de areia", em que as crianças brincavam de jogar areia umas nas outras e ocorreu no S4. As duas de faz de conta também ocorreram no S4 e se constituíram na construção de um monte de areia com a finalidade de ser um bolo - juntamente com a brincadeira do tipo construtiva e na simulação desse elemento ser filtro solar, esfregando-o nos braços.

O segundo elemento da natureza mais utilizado em brincadeiras foi a água, com a ocorrência em quatro brincadeiras turbulentas e quatro brincadeiras construtivas, sendo que uma delas ocorreu juntamente com o elemento areia. As brincadeiras turbulentas ocorreram no $\mathrm{S} 4$ e foram compostas por "guerras de água" - com o uso de pistolas de água de brinquedo - e a agitação de mãos e pés com a finalidade de esparramar água. As brincadeiras construtivas foram observadas nos setores S3 e S4 e envolveram a intenção de formar ondas na água, com ou sem a utilização de potes plásticos. Com quatro ocorrências, o elemento natural pedra - terceiro e último elemento usado pelas crianças - foi utilizado no S4. A pedra apareceu juntamente com a areia nas brincadeiras construtivas, já que as crianças foram observadas depositando a areia sobre a pedra, e em uma brincadeira de faz de conta. 


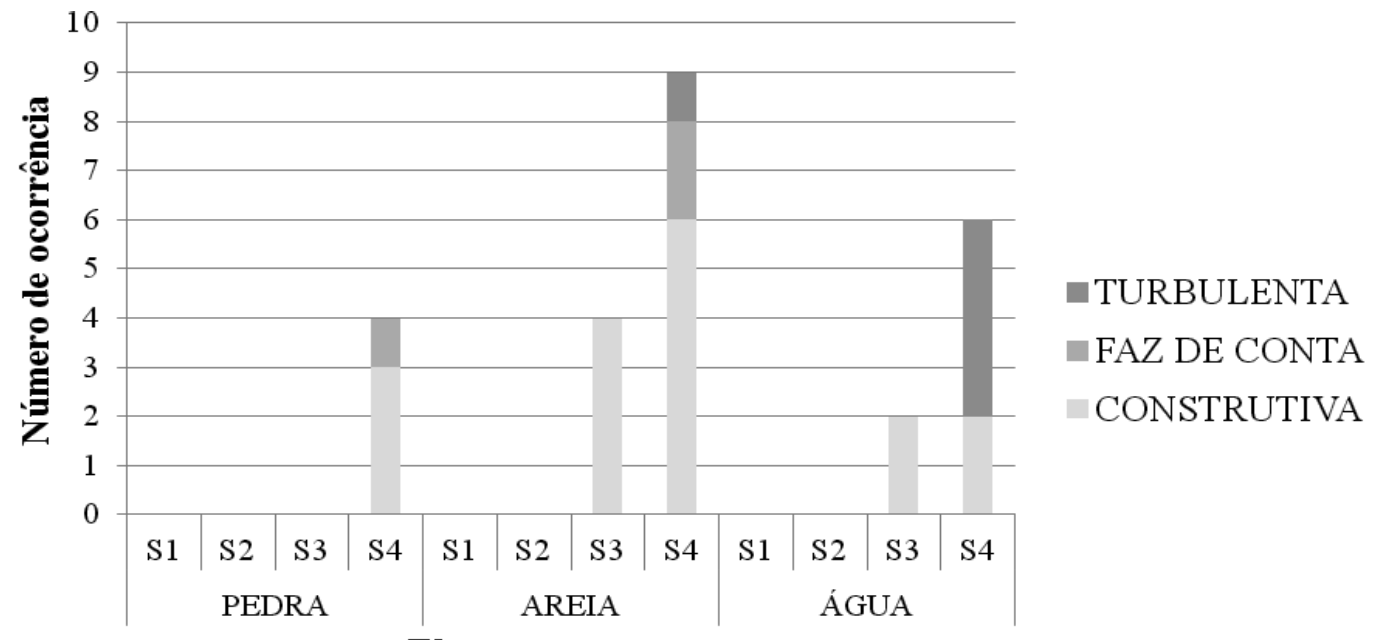

Elementos natureza

Figura 3. Brincadeiras utilizando elementos da natureza no Parque 2.

\section{Discussão}

A areia foi o elemento natural mais utilizado nas brincadeiras construtivas pelas crianças nos dois parques. No Parque 2, a areia foi utilizada nos três tipos de brincadeiras, predominando na brincadeira construtiva, e em seguida, nas brincadeiras turbulenta e faz de conta, que tiveram um número de ocorrências aproximadamente equivalentes. Em observações realizadas por Refshauge et al. (2013), foram identificadas mais brincadeiras do tipo construtivas ocorrendo no espaço de areia de quatro parques infantis públicos da Dinamarca, seguido de brincadeiras funcionais e jogos.

A presença da areia em três tipos de brincadeiras no Parque 2 está possivelmente relacionada às características físicas do local. Ao contrário do Parque 1, no qual a areia estava concentrada em uma caixa de areia como parte do conjunto de equipamentos que compõe o parque infantil, a areia do Parque 2 constitui um recurso natural de uma área de restinga, ou seja, disponível à criança em toda a extensão do parque. Nesse sentido, pode-se inferir que a presença natural de elementos da natureza em uma determinada área resguarda em si um potencial não planejado de oferta de brincadeiras às crianças.

O segundo elemento natural mais utilizado foi a água. A interação com esse elemento foi somente observada no Parque 2. Embora existissem dois lagos no Parque 1, não foram observadas interações das crianças com a água.
Isso possivelmente se deve às características dos lagos que foram espaços construídos para servirem de ambiente para répteis e aves aquáticas. A presença de muretas ao redor dos lagos e o desnível entre o solo e a superfície de água formam uma barreira espacial que dificulta o acesso do visitante a água, permitindo apenas observação do lugar. Este tipo de arranjo espacial comunica um tipo de comportamento aos visitantes, de usar os lagos para observação dos animais e apreciação da paisagem. É importante destacar que a presença da água na composição de paisagens naturais está atrelada ao restauro psicológico e bem-estar dos indivíduos (Velarde, Fry, \& Tveit, 2007).

A água no Parque 2, em contrapartida, era facilmente acessada pelos visitantes do local. A utilização da água nesse parque se dava por uma lagoa natural, cujas características a tornam convidativa para o banho na estação do verão, considerada um dos principais balneários de água doce da Ilha de Santa Catarina. Em outras palavras, a estruturação do parque convida seus visitantes a vivenciar a lagoa, o que ocorre mais efetivamente no verão em decorrência das altas temperaturas. Localizada no S4 no Parque 2, a água foi utilizada por crianças em brincadeiras construtivas e turbulentas, em igual número de ocorrências. O estudo de Refshauge et al. (2013) corrobora esses resultados para os tipos de brincadeiras e reitera que brincadeiras envolvendo esse elemento favorecem a interação e cooperação entre as crianças. 
De acordo com Said (2008), a água também é capaz de auxiliar no desenvolvimento de funções sensoriais, cognitivas, físicas e sociais. Ao observar dez crianças de quatro a doze anos em cinco riachos e rios na Malásia, o pesquisador verificou que a água permitiu quinze atividades diferentes, dentre elas nadar, mergulhar, esparramar água, andar, correr e flutuar. A maioria dessas atividades corresponde à brincadeira turbulenta, que também foram observadas como interações da criança com a água no Parque 2. No presente estudo, destacaram-se as brincadeiras de esparramar água com mãos e pés.

O terceiro elemento mais utilizado foi a pedra e, assim como a água, somente ocorreu no Parque 2. As pedras encontravam-se próximas e dentro da lagoa, sendo mais utilizadas pelas crianças nas brincadeiras construtivas. Esse resultado contrasta com os estudos de Fjørtoft (2004) e Sandseter (2009), realizados na Noruega com crianças de quatro a sete anos, que identificam a pedra como um elemento encontrado na topografia de áreas com mata que possibilita brincadeiras turbulentas como escalar e pular delas. No entanto, Samborski (2010) ao investigar as preferências e percepções em relação ao tipo de solo escolar de 349 crianças de seis a treze anos de duas escolas do Canadá, encontrou que a pedra proporciona todos os três tipos de brincadeiras. As crianças podem escalá-las (brincadeira turbulenta), empilhá-las (brincadeira construtiva) e realizar atividades que envolvam a imaginação, como por exemplo, utilizar a pedra como um forte, nas brincadeiras de espião e de casinha (brincadeira de faz-de-conta). Constatou que além da realização dessas brincadeiras, esse elemento serviu também para as crianças desempenharem atividades mais calmas e introspectivas, utilizando a pedra para sentar, por exemplo. Sendo assim, as diferentes características das pedras permitem determinados tipos de interação. Pedras pequenas e soltas podem ser jogadas na água, utilizadas para construção, enquanto que pedras grandes sugerem outras possibilidades. A localização das pedras no ambiente, a altura e o acesso também influenciam no modo como as crianças irão incluí-las em suas brincadeiras.
O último elemento usado nas brincadeiras foi a vegetação. Ao entrevistar crianças, Jansson (2008) identificou que parques infantis com árvores nos arredores eram os seus lugares preferidos, devido às possibilidades de brincadeiras do tipo turbulenta, como subir, e construtivas, como construir cabanas, que as árvores proporcionavam. Refshauge et al. (2013) observaram a ocorrência de brincadeira turbulenta e de faz de conta em um grupo de meninas de oito e nove anos que subiram em uma árvore e amarraram suas jaquetas nos galhos para servir de rede para seus ursinhos de pelúcia. Sargisson e McLean (2012) observaram 4597 comportamentos infantis em 56 parques na Nova Zelândia e encontraram a atividade de escalar árvores tanto nos meninos quanto nas meninas, apesar de constatarem que $76 \%$ das árvores não eram acessíveis às crianças. Os autores afirmam que, além de ser usada para brincadeiras de escalar, fornecem sombra e em diferentes épocas do ano deixam cair no chão folhas, flores, nozes e outras sementes que podem ser usadas em brincadeiras de faz de conta.

Nesse estudo, a interação com a vegetação somente ocorreu no Parque 1. Embora o Parque 2 tivesse vegetação em abundância, esse elemento não foi incorporado nas brincadeiras. Isso pode ser explicado pela época do ano na qual o estudo foi feito: o verão. Nesse período, a lagoa do parque torna-se um balneário e a vegetação é utilizada como local de abrigo e descanso, principalmente para os cuidadores que monitoram as crianças realizando suas atividades.

\section{Conclusões}

Os elementos naturais que apareceram nas brincadeiras infantis foram: areia, água, pedra e árvore. A areia foi o elemento com o qual as crianças mais interagiram, constituindo-se como único elemento utilizado nos dois parques e que proporcionou todos os três tipos de brincadeiras. Nesse sentido, ressalta-se a importância de preservar a presença da areia em áreas naturais ou incluí-la em áreas planejadas, tendo em vista sua influência na promoção de atividades de recreação infantil. 
A água oportunizou a realização de brincadeiras construtivas e turbulentas em número igual de ocorrências, sendo observada em apenas um dos parques. A pedra possibilitou brincadeiras construtivas e do tipo faz de conta, com maior ocorrência das construtivas, apenas observadas no Parque 2. A árvore proporcionou a brincadeira do tipo turbulenta no Parque 1. A interação indireta com animais - que não se constituiu como brincadeira por não haver o toque com as mãos - foi observada nos dois parques.

As diferenças observadas entre os parques quanto a frequência de interação com a natureza são possivelmente resultantes das características físicas dos espaços. No Parque 1, a presença de barreiras físicas limitou a interação das crianças com a água e a presença da areia apenas na área do parque infantil restringiu o seu uso. No Parque 2, a areia era um elemento não planejado e presente por toda a extensão do parque, proporcionando maior diversidade de brincadeiras. Além disso, a água do Parque 2 era também um recurso acessível pela presença de uma lagoa que oferecia condições para banho, o que elevou a interação das crianças com esse elemento natural.

Conclui-se que quando a natureza está acessível à criança, ela a incorpora nas suas brincadeiras. Este estudo e a literatura discutida identificam uma variedade de brincadeiras que são realizadas com elementos da natureza. Isso mostra que a natureza de muitos espaços abertos como dos parques urbanos adquire além de uma função estética e ecológica, uma função de lazer. Recursos naturais como areia, água, pedra e árvore são elementos que, dependendo de suas características particulares, podem ser incorporados no planejamento de espaços de lazer infantis de modo a promover uma diversidade de brincadeiras, sejam estas turbulentas, construtivas ou faz-de-conta.

\section{Referências}

Azlina, W., \& Zulkiflee, A. S. (2012). A pilot study: The impact of outdoor play spaces on kindergarten children. Procedia - Social and Behavioral Sciences, 38, 275-283. doi:10.1016/j. sbspro.2012.03.349
Chawla, L. (1998). Significant life experiences revisited: A review of research on sources of environmental sensitivity. Journal of Environmental Education, 31, 15-26. doi:10.1080/00958969809599114

Chawla, L. (2007). Childhood experiences associated with care for the natural world: A theoretical framework for empirical results. Children, Youth and Environments, 17(4), 144-170. Retrieved from http://www.jstor.org/discover/10.7721/ chilyoutenvi.17.4.0144

Collado, S., Staats, H., \& Corraliza, J. A. (2013). Experiencing nature in children's summer camps: Affective, cognitive and behavioural consequences. Journal of Environmental Psychology, 33, 37-44. doi:10.1016/j.jenvp.2012.08.002

Cordazzo, S. T. D., Westphal, J. P., Tagliari, F. B., Vieira, M. L., \& Oliveira, A. M. F. (2008). Metodologia observacional para o estudo do brincar na escola. Avaliação Psicológica, 7(3), 427438. Recuperado em http://www.redalyc.org/ pdf/3350/335027185014.pdf

Czalczynska-Podolska, M. (2014). The impact of playground spatial features on children's play and activity forms: An evaluation of contemporary playgrounds'play and social value. Journal of Environmental Psychology, 38, 132-142. doi:10.1016/j.jenvp.2014.01.006

Dyment, J. E., \& Bell, A. C. (2008). Grounds for movement: Green school grounds as sites for promoting physical activity. Health Education Research, 23(6), 952-962.

Fagundes, A. J. F. M. (1999). Descrição, definição e registro de comportamento (12. ed.). São Paulo, SP: EDICON.

Fernandes, O. S., \& Elali, G. A. (2008). Reflexões sobre comportamento infantil em um pátio escolar: O que aprendemos observando as atividades das crianças. Paidéia (Ribeirão Preto), 18(39), 4152. doi:10.1590/S0103-863X2008000100005

Fiaes, C. S., \& Bichara, I. D. (2009). Brincadeiras de faz de conta em crianças autistas: Limites e possibilidades numa perspectiva evolucionista. Estudos de Psicologia (Natal), 14(3), 231-238. doi:10.1590/S1413-294X2009000300007

Fjørtoft, I. (2004). Landscape as Playscape: The effects of natural environments on children's play and motor development. Children, Youth and Environments, 14(2), 21-44. Retrieved from http://www.jstor.org/stable/10.7721/chilyouten vi.14.2.0021?seq=1\#page_scan_tab_contents 
Fjørtoft, I., Kristoffersen, B., \& Sageie, J. (2009). Children in schoolyards: Tracking movement patterns and physical activity in schoolyards using global positioning system and heart rate monitoring. Landscape and Urban Planning, 93, 210-217. doi:10.1016/j.landurbplan.2009.07.008

Fundo das Nações Unidas para a Infância. (2012). Situação mundial da infância 2012: Crianças em um mundo urbano (Relatório). Recuperado em http://www.unicef.org/brazil/pt/PT-BR_ SOWC_2012.pdf

Hansen, J., Macarini, S. M., Martins, G. D. F., Wanderlind, F. H., \& Vieira, M. L. (2007). O brincar e suas implicações para o desenvolvimento infantil a partir da psicologia evolucionista. Revista Brasileira de Crescimento e Desenvolvimento Humano, 17(2), 133-143. Recuperado em http://pepsic.bvsalud.org/pdf/ rbcdh/v17n2/14.pdf

Jansson, M. (2008). Children's perspectives on public playgrounds in two Swedish communities. Children, Youth and Environments, 18(2), 88-109. Retrieved from http://www.colorado. edu/journals/cye/18_2/18_2_04_SwedishPlaygrounds.pdf

Kahn, P., Jr. (2002). Children's affiliations with nature: Structure, development, and the problem of environmental generational amnesia. In P. H. Kahn Jr. \& S. R. Kellert (Eds.), Children and nature: Psychological, sociocultural, and evolutionary investigations (pp. 93-116). Cambridge, MA: The Massachusetts Institute of Technology Press.

Kernan, M. (2010). Outdoor affordances in early childhood education and care settings: Adult's and children's perspectives. Children, Youth and Environments, 20(1), 152-177. Retrieved from http://www.jstor.org/discover/10.7721/chilyoutenvi.20.1.0152

Korpela, K., Kÿtta, M., \& Hartig, T. (2002). Restorative experience, self-regulation, and children's place preferences. Journal of Environmental Psychology, 22, 387-398. doi:10.1006/jevp.2002.0277

Kuh, L. P., Ponte, I., \& Chau, C. (2013). The impact of a natural playscape on young children's play behaviors. Children, Youth and Environments, 23(2), 49-77. Retrieved from http://www.jstor. org/discover/10.7721/chilyoutenvi.23.2.0049
Luz, G. M., \& Kuhnen, A. (2013). O uso dos espaços urbanos pelas crianças: Explorando o comportamento do brincar em praças públicas. Psicologia Reflexão e Crítica, 26(3), 552-560. doi:10.1590/ S0102-79722013000300015

Malone, K., \& Tranter, P. (2003). Children's environmental learning and the use, design and management of schoolgrounds. Children, Youth and Environments, 13(2), 1-45. Retrieved from http://www.jstor.org/discover/10.7721/chilyoutenvi.13.2.0087

Pinheiro, J. Q., Elali, G. A., \& Fernandes, O. S. (2008). Observando a interação pessoa-ambiente: Vestígios ambientais e mapeamento comportamental. In J. Q. Pinheiro \& H. Günther (Eds.), Métodos de pesquisa nos estudos pessoa-ambiente (pp. 75-104). São Paulo, SP: Casa do Psicólogo.

Pinho, L. F. S. V. (2004). A agressividade e o conflito nas brincadeiras entre crianças em situação de risco social (Dissertação de mestrado, Universidade Católica de Goiás, Goiânia, GO, Brasil).

Rasmussen, K. (2004). Places for children-children's places. Childhood, 11(2), 155-173. doi:10.1177/0907568204043053

Raymundo, L. S., Kuhnen, A., \& Soares, L. B. (2011). O espaço aberto da educação infantil: Lugar para brincar e desenvolver-se. Psicologia em Revista, 16, 251-270. doi:10.5752/P.16789563.2010v16n2p251

Refshauge, A. D., Stigsdotter, U. K., \& Petersen, L. S. (2013). Play and behavior characteristics in relation to the design of four Danish public playgrounds. Children, Youth and Environments, 23(2), 22-48. Retrieved from http://www.jstor. org/stable/10.7721/chilyoutenvi.23.2.0022

Romero, A. J., Robinson, T. N., Kraemer, H. C., Erickson, S. J., Haydel, F., Mendozo, F., \& Killen, J. D. (2001). Are perceived neighborhood hazards a barrier to physical activity in children? Archives of Pediatrics \& Adolescent Medicine, 155, 1143-1148. doi:10.1001/archpedi.155.10.1143

Said, I. (2008). Evaluating affordances of streams and rivers pertaining to children's functioning in natural environments. Journal of King Saud University-Architecture and Planning Division, 20. Retrieved from http://eprints.utm. my/3738/1/river_affordances.pdf 
Samborski, S. (2010). Biodiverse or Barren School Grounds: Their effects on children. Children, Youth and Environments, 20(2), 67-115. Retrieved from https://dspace.library.uvic.ca:8443/ bitstream/handle/1828/4336/20_2_04_BiodiverseOrBarren.pdf?sequence $=1 \&$ isAllowed $=\mathrm{y}$

Sandseter, E. B. H. (2009). Affordances for risky play in Preschool: The importance of features in the play environment. Early Childhood Education Journal, 36, 439-446.

Santos, A. K., \& Dias, A. M. (2010). Comportamentos lúdicos entre crianças do nordeste do Brasil: Categorização de brincadeiras. Psicologia: Teoria e Pesquisa, 26(4), 585-594. Recuperado em http://www.scielo.br/pdf/ptp/v26n4/02.pdf

Sargisson, R. J., \&. McLean, I. G. (2012). Children's use of nature in New Zealand playgrounds. Children, Youth and Environments, 22(2), 144163. Retrieved from http://www.colorado.edu/ journals/cye/22_2/22_2_07_NewZealandPlaygrounds.pdf

Schäffer, S. D., \& Kistemann, T. (2012). Reconceptualizing school design: Learning environments for children and youth. Children, Youth and Environments, 22(1), 270-279. Retrieved from http://www.jstor.org/discover/10.7721/chilyoutenvi.22.1.0270

Timperio, A., Salmon, J., Telford, A., \& Crawford, D. (2005). Perceptions of local neighborhood environments and their relationship to childhood overweight and obesity. International Journal of Obesity, 29, 170-175. doi:10.1038/ sj.ijo.0802865

Valentine, G., \& McKendrick, J. (1997). Children's outdoor play: Exploring parental concerns about children's safety and the changing nature of childhood. Geoforum, 28(2), 219-235. Retrieved from http://ynckelowna.weebly.com/ uploads/1/3/2/0/13208868/childrens_outdoor_ play.pdf
Velarde, M. D., Fry, G., \& Tveit, M. (2007) Health effects of viewing landscapes: Landscape types in environmental psychology. Urban Forestry \& Urban Greening, 6(4), 199-212. Retrieved from http://www.friskinaturen.org/media/landscape_ viewing..._2_bs.pdf

Wang, F., Liu, J., Pan, B., Zhao, L., \& Zhang, M. (2012). Stuck between the historic and modern China: A case study of children's space in a hutong community. Journal of Environmental Psychology, 32(1), 59-68. doi:10.1016/j.jenvp.2011.10.001

Wells, N. M. (2000). At home with nature: Effects of "greenness" on children's cognitive functioning. Environment and Behavior, 32(6), 775-795. doi:10.1177/00139160021972793

Wells, N. M., \& Evans, G. W. (2003). Nearby nature: A buffer of life stress among rural children. Environment and Behavior, 35(3), 311-330. doi:10.1177/0013916503035003001

Yamamoto, M. E., \& Carvalho, A. M. A. (2002). Brincar para quê? Uma abordagem etológica ao estudo da brincadeira. Estudos de Psicologia (Natal), 7(1), 163-164. Recuperado em http:// www.redalyc.org/articulo.oa?id=26170116
Recebido: $21 / 11 / 2014$

$1^{a}$ revisão: $14 / 05 / 2015$ Aceite final: 10/06/2015 